\title{
Memória educacional no município de Enéas Marques- PR: décadas de (1960-1990) - Das escolas rurais à nuclearização
}

\author{
Maricélia Aparecida Nurmberg ${ }^{1}$, André Paulo Castanha ${ }^{2}$ \\ ${ }^{1}$ Universidade Estadual do Oeste do Paraná - UNIOESTE. Programa de Pós-Graduação em Educação. Rua \\ Maringá, 1200, Vila Nova. Francisco Beltrão - PR. Brasil. ir.maricelia@ hotmail.com. ${ }^{2}$ Universidade Estadual do \\ Oeste do Paraná - UNIOESTE.
}

\begin{abstract}
RESUMO: As pesquisas sobre história regional e escolas rurais são recentes, principalmente no Sudoeste do Paraná. Ainda carecem de incentivo e novos pesquisadores que se dediquem a desvelar esta história, com pesquisas pautadas em fontes documentais e/ou orais. Este texto foi produzido a partir de referenciais bibliográficos, fontes documentais e depoimentos orais, procurando registrar a história da Educação do município de Enéas Marques, situado no Sudoeste do Paraná entre as décadas de 1960 a 1990, período em que o número de escolas rurais era muito expressivo. Estas escolas eram em sua maioria multisseriadas, funcionando em dois períodos, sendo atendidas por um ou dois professores. Contudo, a partir da década de 1990, iniciou-se o processo de fechamento/nuclearização destas escolas e os alunos passaram a utilizarem-se do transporte escolar, com isso, a maioria deles foram estudar em escolas urbanas, fazendo com que a identidade rural fosse se perdendo.
\end{abstract}

Palavras-chave: Educação Rural, Nuclearização Escolar, Sudoeste do Paraná. 


\title{
Education memory of Enéas Marques municipality-PR: 1960-1990: From rural schools to nuclear
}

\begin{abstract}
Research on regional history and rural schools is recent, mainly in the Southwest of Paraná. They still lack the incentive and new researchers who dedicate themselves to unveiling this story, with research based on documentary or oral sources. This text was produced from bibliographical references, oral testimonies and documentary sources and sought to record the history of Education in the city of Enéas Marques, located in the Southwest of Paraná, between the 1960s and 1990s, a period in which the number of rural schools was very expressive. These schools were, in their majority, multiseriates, functioning in two periods and being attended by one or two teachers. However, from the 1990s, the process of closing/nuclearization of these schools began, and students began to use school transport, with the result that most of them went to study in urban schools, making the rural identity was getting lost.
\end{abstract}

Keywords: Rural Education, School Nuclearization, Southwest of Paraná. 


\section{Memoria educacional en el municipio de Enéas Marques- PR: 1960-1990: De las escuelas rurales a la nuclearización}

RESUMEN: Las investigaciones sobre historia regional y escuelas rurales son recientes, principalmente en el Sudoeste del Paraná. Todavía carecen de incentivo y nuevos investigadores que se dediquen a desvelar esta historia, con averiguaciones pautadas en fuentes documentales y orales. Este texto fue producido a partir de referencias bibliográficas, testimonios orales y fuentes documentales y buscó registrar la historia de la Educación del municipio de Enéas Marques, situado en el Sudoeste de Paraná entre las décadas de 1960 a 1990 etapa en que el número de escuelas rurales era muy expresivo. Estas escuelas eran en su mayoría con distintos niveles de aprendizaje, funcionando en dos períodos siendo atendidas por uno o dos profesores. Sin embargo, a partir de la década de 1990 se inició el proceso de cerramiento/nuclearización de estas escuelas y los alumnos pasaron a utilizar del transporte escolar, con eso, la mayoría de ellas fue a estudiar en escuelas urbanas, haciendo que la identidad rural fuese se perdiendo.

Palabras clave: Educación Rural, Nuclearización Escolar, Sudoeste de Paraná. 


\section{Introdução}

As pesquisas sobre as instituições escolares são recentes e se intensificaram a partir da década de 1990 dentro dos cursos de Pós-graduação. Tais pesquisas são importantes porque contribuem para resgatar a memória das instituições escolares e sua relação com a sociedade, para desvelar as relações cotidianas em sala de aula, a organização das escolas, bem como o contexto que levou a consolidação ou fechamento de tais instituições.

Este artigo resultou da investigação da história da Educação do Município de Enéas Marques entre as décadas de 1960 e 1990 a partir de documentos e depoimentos orais, visando contribuir com a preservação da história educacional do município. Os objetivos foram: catalogar os documentos históricos para construir um acervo documental digital sobre a História da Educação do município de Enéas Marques; Mapear as instituições escolares e sua função social no período; Preservar a história oral dos envolvidos no processo de constituição do município e das instituições escolares, para que a história não fique esquecida, ou seja, perdida pela falta de pesquisadores e divulgadores. Seu desenvolvimento pautou-se nas fontes documentais e fontes orais. A pesquisa também está alicerçada em fontes bibliográficas, as quais permitiram as articulações entre as questões nacionais, estaduais e locais. A técnica de produção de dados se deu pelo cruzamento das informações e pela análise de conteúdo dos documentos levantados e das entrevistas realizadas.

Procuramos entender e analisar como ocorreu o processo de povoamento de Enéas Marques e a constituição das escolas por meio da seguinte metodologia: a) Investigação nas fontes primárias: leis, decretos, resoluções, atas escolares, diários de classe, relatórios finais, documentos diversos, registros de matrículas, exames finais, dados estatísticos, fotografias, jornais e revistas; b) Levantamento bibliográfico: artigos, livros, dissertações; trabalhos; c) Entrevistas com ex-prefeito, ex-professores, pais e pioneiros da comunidade.

A base teórica para análise e investigação foi o materialismo históricodialético. Partimos da coleta e análise dos dados, o contexto histórico que permeou o processo de constituição das escolas, buscando captar sua totalidade, desvelar os fatores sociais, econômicos, religiosos, históricos, culturais e políticos que permearam o desenvolvimento da educação. Conforme Netto: “começa-se pelo 'real e pelo concreto', que aparecem 
como dados; pela análise, um e outro elemento são abstraídos e, progressivamente, com o avanço da análise, chega-se a conceitos, a abstrações" (Netto, 2011, p. 42). Segundo Nosella e Buffa: "para o método dialético, o fundamental em pesquisas sobre instituições escolares, é relacionar o particular (o singular, o dado empírico) com o geral, isto é, com a totalidade social" (Nosella \& Buffa, 2006, p. 362).

De acordo com Netto (2011), o que determina os procedimentos a serem seguidos pelo pesquisador é a estrutura e dinâmica do objeto. Segundo o autor, "o método implica, pois, para Marx, uma determinada posição (perspectiva) do sujeito que pesquisa: aquela em que se opõe o pesquisador para, na sua relação com o objeto, extrair dele as suas múltiplas determinações" (Netto, 2011, p. 53).

Buscou-se a partir do contexto histórico, político, social, local, regional e nacional, identificar as escolas existentes no passado, quem foram os mentores ou organizadores, como eram estruturadas e organizadas, quem eram os professores, perfil dos alunos atendidos, bem como quais as instituições que ainda estão em funcionamento. Este texto expressa uma síntese dessa pesquisa ampla sobre a educação em Enéas Marquesi ${ }^{i}$
Em sua maioria, as escolas foram construídas pelo governo municipal contando com a participação dos pais de alunos. A maior parte era localizada na zona rural, representando um número grande de escolas, visto que Enéas Marques era e é um município pequeno a nível populacional, com predominância da população rural. Segundo Cattelan (2014), em 1954 foram construídas no município de Francisco, ao qual Enéas Marques estava vinculado, várias escolas seguindo o mesmo padrão: “o padrão ' $A$ ' era construído por uma sala de aula $8 \times 12$ metros com tábuas beneficiadas, paredes duplas pintadas a óleo e cobertas de telhas francesas" (Cattelan, 2014, p. 125).

Essas escolas rurais, em sua maioria, foram cessadas a partir da década de 1990. Além destas escolas, identificou-se uma escola coordenada por religiosas, com a participação de sacerdotes na coordenação e execução de escolas de $1^{\circ}$ e $2^{\circ} \mathrm{Grau}$, por meio de convênios com entidades. Estes foram alguns elementos que nos instigaram a investigar como ocorreu o processo de constituição e fechamento das Instituições Escolares do município de Enéas Marques entre as décadas de 1960-1990.

Por meio da metodologia de "história oral" deu-se voz a pessoas que participaram do processo de construção do município de Enéas Marques e da 
organização da educação, pois não foram encontrados estudos específicos sobre a história das escolas do município. Há algumas menções em documentos das escolas quando pertenciam a Francisco Beltrão, antes de 1964, data de sua emancipação. As fontes orais foram relevantes, pois, a maioria dos pioneiros e professores das escolas que fecharam, residem, ainda, no município.

A partir dos dados coletados nos documentos, encontraram-se nomes de professores e pessoas residentes do município que foram selecionadas para a entrevista, tendo como suporte a metodologia da História Oral. Inicialmente, realizamos uma visita a estas pessoas para apresentar o projeto e os objetivos, ouvi-las e saber se gostariam de participar do mesmo, contando suas memórias. Felizmente, tais pessoas foram muito abertas e acolhedoras à proposta e ficaram felizes em contar suas lembranças. Após a visita organizamos um roteiro de questões que seriam feitas a cada entrevistado. Em nova visita realizamos as entrevistas de forma gravada, depois transcrevemos e fizemos pequenos ajustes, devido as repetições ou erros de pronúncia. Concluída esta parte, voltamos à casa dos entrevistados com o texto transcrito. Depois de lido e aprovado, colhemos a assinatura no termo de cessão, para fazermos uso do material. No texto, utilizamos alguns excertos das entrevistas, as quais, juntamente com os documentos, são as fontes que dispomos para conhecer a realidade pesquisada.

Ouvindo uma pessoa podemos apreender suas memórias e experiências, que pode ser também de uma localidade ou região. Segundo Le Goff (1990, p. 477), “a memória, onde cresce a história, que por sua vez a alimenta, procura salvar $\mathrm{o}$ passado para servir o presente e o futuro. Devemos trabalhar de forma a que a memória coletiva sirva para a libertação e não para a servidão dos homens". Por meio da memória, o passado permanece vivo na lembrança das pessoas. Para Le Goff (1990), a memória serve para a libertação ou para a servidão, depende qual aspecto é enfocado. Para o autor a memória é também um instrumento de poder.

Memórias ouvidas que podem ser memórias de muitos. Memórias que precisam ser ouvidas e preservadas para não ficarem esquecidas e também para que a história seja reconstruída e contada para as novas gerações. Memórias de vidas, de escolas, de fatos e de gente, que se constituíram em fontes históricas.

Para dar conta do objetivo organizamos o texto com os seguintes tópicos: Enéas Marques no cenário do Sudoeste do Paraná; criação das escolas 
rurais no município de Enéas Marques; e processo de nuclearização das escolas rurais.

\section{Enéas Marques no cenário do Sudoeste do Paraná}

O município de Enéas Marques está localizado no Sudoeste do Paraná. Tem uma população de 6.195 habitantes segundo estimativas do IBGE de 2015, e uma área de 192, 203 Km².

Pela Lei $n^{\circ}$ 92, de 25 de agosto de 1961, a vila Jaracatiáii foi elevada à categoria de Distrito Administrativo de Francisco Beltrão e, em 18 de fevereiro de 1964, pela Lei Estadual nº 4.823 foi criado o Município, passando a chamar-se Enéas Marques iii e sendo desmembrado do território de Francisco Beltrão. A partir da emancipação intensificou-se a estruturação do município, a construção de estradas, escolas, Igreja, hospital etc.

Até a emancipação de Enéas Marques, as escolas permaneceram vinculadas a Francisco Beltrão. No ano de 1964, havia em funcionamento 26 escolas, número este que foi crescendo e na década de 1980 até 1990 havia registros de 53 escolas, visto que estava englobado o território de Nova Esperança do Sudoeste, emancipado de Enéas Marques em 1992, pela Lei $n^{\circ}$ 9.915. Foi nesse momento em que se intensificou $o$ processo de nuclearização das escolas rurais em toda a região do Sudoeste do Paraná.

Na década de 1940, todo o território que compõe os municípios da região Sudoeste do PR pertencia ao município de Clevelândia. Foi nesse período que teve início o processo de colonização e povoamento dessa região de forma mais acentuada. Como atesta Padis, “... embora, desde a terceira década deste século, se pudesse encontrar gaúchos em terras do sudoeste paranaense, foi a partir de 1952, e especialmente depois de 1956, que esse movimento migratório se intensificou de forma surpreendente" (Padis, 1981, p. 152).

Até a década de 1940 essa região era uma mata extensa, apresentando uma diversidade de árvores e plantas nativas, habitada esporadicamente por indígenas. Niederheitmann (1986) discorre que na década de 1940 teve início o povoamento da região que inicialmente era pertencente ao território de Francisco Beltrão e, mais tarde, tornaram-se os municípios vizinhos de Enéas Marques, Nova Prata do Iguaçu, Salto do Lontra e Nova Esperança do Sudoeste.

O povoamento do distrito Jaracatiá foi semelhante ao dos demais municípios da Região Sudoeste do Paraná, colonizado majoritariamente por famílias vindas do Rio Grande do Sul e Santa Catarina em 
busca de melhores condições de vida e sobrevivência, para tanto, buscaram terras para plantar e de onde retirar sua subsistência. Como afirmado na publicação Enéas Marques em Revista:

O lugar foi colonizado rapidamente pelos colonos vindos do sul, Santa Catarina e Rio Grande; eram influenciados também pelas facilidades oferecidas pela Cango (Colônia Agrícola Nacional General Osório), do governo federal, que marcava o sítio e ajudava as famílias por um determinado período com ferramentas, alimentação, assistência médica e educação (Enéas Marques, Revista, 1988, p. 5).

\section{A CANGO (Colônia Agrícola}

Nacional General Osório) foi criada em 1943 e sua instalação definitiva em Francisco Beltrão ocorreu em 1948. Segundo Cattelan, “em 1938, o presidente Getúlio Vargas, intensificou a política de ocupação de espaços vazios, conhecida como 'Marcha para o Oeste', a fim de colonizar o interior do Brasil" (Catellan, 2014, p. 27). Para efetivar a política de colonização criou as Colônias e Territórios Federais. Conforme Cattelan:

Como suporte para a colonização e base de apoio para esta política criou as Colônias e Territórios Federais. No Paraná, criou-se a CANGO, em 1943, pelo decreto $\mathrm{n}^{\circ} 12.417$. Ela se instalou primeiramente em Pato Branco e, posteriormente na pequena Vila Marrecas. Segundo os relatórios, a CANGO fornecia lotes de terras gratuitos para os migrantes, além de sementes e ferramentas para o trabalho na agricultura. A CANGO foi responsável pela criação das primeiras escolas (Cattelan, 2014, p. 27).

A vinda até o Sudoeste ocorreu de maneira quase semelhante para a maioria que aqui migrou: dias em cima de caminhão, carroça ou cargueiro, com alguns pertences e alimentos, enfrentando as intempéries, sol e chuva, abrindo picadas na mata e se deslocando a pé, percorrendo grandes distâncias, depois trazendo seus pertences nos ombros, em cima de lombos de bois ou cavalos. Conforme Mendes (2016), "meus pais vieram abrindo estradas de foice, facão, enxada, para poder chegar ali com a carrocinha trazendo seus pertences".

Os migrantes tinham consciência de que essas terras eram férteis, mas que ao chegarem não teriam amparo e precisariam prover o sustento para suas famílias. Até que essas terras fossem preparadas e semeadas, para a colheita, teriam que ter de onde tirar ou prover os alimentos. Traziam consigo alguns provimentos e dinheiro para que suas famílias não passassem necessidades. Conforme Wessling, "trouxemos junto alguns porcos para criar e a vaca de leite. Daí fizemos uma mangueirinha com o vizinho para criar os 
porcos e comesemo a vida assim"iv (cf. Laste, 2000, p. 102-103).

As terras da região Sudoeste quando da chegada dos migrantes em Enéas Marques eram propriedade do governo federal, administradas pela CANGO, que as distribuía aos colonos que aqui chegavam.

Segundo Martins (1986), para demarcar o território, os agentes da CANGO abriram picadas por entre as matas e construíram sua sede no lado esquerdo do Rio Marrecas, havia escritórios, hospedarias, refeitório, instalações médicas etc. Conforme Cattelan (2014), a organização dos Núcleos Coloniais foi fixada pelo DecretoLei $\mathrm{n}^{\circ}$ 2.009, de 09 de fevereiro de 1940: "sendo estes definidos como uma reunião de lotes medidos e demarcados, criados pela União, Estados, Municípios e por empresas particulares, a fim de acolher agricultores em pequenas propriedades" (Cattelan, 2014, p. 44).

Com base em demandas judiciais anteriores, em 1951 instalou-se na região a Clevelândia Industrial Territorial Ltda (CITLA) que passou a exigir dos colonos o pagamento pela ocupação destas terras com a alegação de que era a verdadeira proprietária.

De acordo com Lazier, "os emissários da CITLA apareceram como proprietários das glebas Chopim e Missões, e passaram a vender a referida área aos posseiros e demais interessados. Para tanto, instalou escritórios no Sudoeste" (Lazier, 1997, p. 27).

Conforme Niederheitmann (1986), "para acelerar e dividir as atividades de loteamento da área, em janeiro de 1957, organizaram-se duas grandes companhias imobiliárias: Companhia Comercial e Agrícola Paraná LTDA (COMERCIAL) e Companhia Colonizadora Apucarana (APUCARANA)" (Niederheitmann, 1986, p. 42). Os funcionários dessas companhias visitavam as propriedades exigindo dos posseiros a assinatura de documentos de compra e venda das terras. Aqueles que se recusavam a assinar ou pagar sofriam violência ou levavam algo de suas colheitas ou rebanho, como pagamento. Aos poucos os posseiros e comerciantes da região foram se organizando e manifestando-se contrários as ações dos "jagunços" enviados pelas companhias colonizadoras. Situação vivenciada não tão intensamente pelos moradores da região de Enéas Marques, como os habitavam na região de Francisco Beltrão, Verê, Santo Antônio e Pato Branco.

Conforme Lazier, "cansados de serem roubados, cansados de serem massacrados, cansados de injustiças, os posseiros e o povo do Sudoeste do Paraná 
resolveram colocar um paradeiro naquele estado de coisas, fazendo justiça com suas próprias mãos" (Lazier, 1997, p. 58).

No dia 10 de outubro houve uma mobilização em Francisco Beltrão que ficou conhecida como Revolta dos Posseiros de $1957 . \quad$ Segundo Niederheitmann (1986), os colonos depredaram os escritórios da CITLA e da COMERCIAL, obrigando os funcionários e jagunços a abandonarem os escritórios. Os papéis e promissórias que os jagunços obrigavam os colonos a assinar como compromisso pelo pagamento das terras que usufruíam, foram jogados nas ruas. Nos dias seguintes também se mobilizaram em Pato Branco e Santo Antonio do Sudoeste. Conforme indicou Lazier, "os posseiros venceram as companhias colonizadoras que atuavam como grileiras e apoiadas pelo Governador do Paraná" (Lazier, 1997, p. 63).

Após a expulsão das companhias colonizadoras, os municípios foram sendo organizados e emancipados, e a região Sudoeste teve sua população ampliada consideravelmente, os agricultores puderam estabelecer-se e trabalhar com afinco para prover o sustento de suas famílias.

Padis (1981) traz alguns dados sobre a população dos municípios do Sudoeste nas décadas de 1940, 1950 e 1960 a partir de uma tabela intitulada "evolução da população no sudoeste paranaense": apresenta dados de 63 municípios do Sudoeste e Oeste do Paraná e a existência ou não de habitantes. Conforme podemos observar no quadro:

Quadro 1: Evolução da População do Sudoeste Paranaense a partir dos municípios oriundos de Clevelândia.

\begin{tabular}{|l|c|c|c|c|}
\hline \multicolumn{1}{|c|}{ MUNICÍPIOS } & $\mathbf{1 9 4 0}$ & $\mathbf{1 9 5 0}$ & $\mathbf{1 9 6 0}$ & $\mathbf{1 9 7 0}$ \\
\hline Clevelândia & 17.240 & 53.977 & 23.634 & 13.911 \\
\hline Barracão & - & - & 14.954 & 18.430 \\
\hline Santo Antônio do Sudoeste & - & - & 26.263 & 28.789 \\
\hline Capanema & - & - & 29.300 & 21.796 \\
\hline Pato Branco & - & - & 51.581 & 34.280 \\
\hline Francisco Beltrão & - & - & 55.498 & 37.280 \\
\hline Enéas Marques & - & - & - & 12.719 \\
\hline
\end{tabular}

Fonte: IBGE, 1970/Padis, 1981, p. 162.

Conforme dados apresentados pelo autor, na década de 1940 e 1950 havia no Sudoeste somente o município de Clevelândia. No ano de 1960, já havia outros municípios: Barracão, Santo
Antônio do Sudoeste, Capanema, Pato Branco e Francisco Beltrão, desmembrados de Clevelândia. O autor justifica que “... os municípios para os quais não há indicação de área e população não estavam ainda 
criados" (Padis, 1981, p. 163), como é o caso de Enéas Marques (Jaracatiá). O distrito Jaracatiá já possuía alguns moradores, mas como estava vinculado ao território de Francisco Beltrão, possivelmente estão contabilizados neste índice de habitantes da população de Francisco Beltrão, visto que foi emancipado somente em 1964. A queda da população nos municípios de Capanema, Pato Branco e Francisco Beltrão, entre 1960 e 1970, se deu pela emancipação de novos municípios, que, a partir do censo de 1970 entraram nas estatísticas com população própria, como foi o caso de Enéas Marques.

\section{Criação das Escolas Rurais no município de Enéas Marques}

Quando Enéas Marques foi emancipado de Francisco Beltrão em 1964, já havia escolas funcionando no município que iniciaram suas atividades na década de 1950. Segundo Damasceno e Beserra (2004), somente a partir da década de 1930 e, mais sistematicamente, das décadas de 1950 e 1960, o problema da educação rural foi encarado mais seriamente. Para as autoras "a educação rural no Brasil tornase objeto do interesse do Estado justamente num momento em que todas as atenções e esperanças se voltam para o urbano e a ênfase recai sobre o desenvolvimento industrial" (Damasceno \& Beserra, 2004, p. 75).

Segundo Cattelan (2014), por volta de 1953 já havia escolas em funcionamento nas comunidades que atualmente pertencem a Enéas Marques, como foi o caso da Escola de Vista Alegre, que iniciou suas atividades em 04 de novembro de 1953, onde atuava a professora Plácida Adria. Segundo a mesma autora, em 1954, a prefeitura municipal de Francisco Beltrão criou 20 escolas e contratou os professores, sendo que alguns deles ministraram aulas em localidades pertencentes a Enéas Marques após a emancipação. Pelo depoimento de Baio (2016) podemos identificar outras duas escolas no antigo Jaracatiá, que não se encontrou documentos sobre sua existência no município de Enéas Marques:

Era uma casinha muito pequena, eu desconfio uma igreja e que depois se transformou em escola. Foi nessa casa que a minha irmã começou a dar aula e depois logo em seguida eles construíram uma escola na frente onde hoje é a Praça Jaracatiá. Quando a minha irmã deu aula nessa escolinha, era de $1^{\mathrm{a}}$ a $4^{\mathrm{a}}$ tudo junto numa sala só. Ensinava as quatro classes. Depois fizeram essa escolinha bem na frente da Igreja do outro lado da Avenida e tinha outra professora que eu não lembro o nome e foi distribuída algumas turmas $1^{\mathrm{a}} \mathrm{e}$ $2^{\mathrm{a}}, 3^{\mathrm{a}}$ e $4^{\mathrm{a}}$ e depois logo em seguida foi construído o Educandário $o$ Colégio das Irmãs ${ }^{v}$ (Baio, 2016). 
Nessa primeira escola, que fora utilizada como igreja e escola, conforme Baio (2016) uma das professoras era Mafalda Wessler, e quando esta casou e mudou-se foi substituída por outra irmã, Iva Wessler. Essas escolas tiveram um período curto de funcionamento, de 1954 até 1962, quando foi inaugurado o Educandário São José. Segundo Marques (2016):

Em 1952 começou a funcionar uma escolinha na sede do Jaracatiá. Construída de madeira de pinho lascada e coberta de taboinhas, assim como todas as casas da época. Era uma igrejinha que passou a ser também escola, com 2 filas de bancos longos onde se acomodavam 4 a 5 alunos em cada. Era multisseriada, da alfabetização ao $3^{\circ}$ ano. A professora era a Sra Silvia Brusamarelo.

No depoimento de Wessling (2016) também há a referência a duas escolas: "em frente da igreja não sei se foi a prefeitura ou o estado que construiu uma escola e daí a CANGO construiu outra escola pra lá da Igreja, as direita, do lado de cima da rua onde é a praça hoje". Segundo ele, algumas professoras dessas escolas foram Silvia Blusamarelo, Laura Rech e Maria Schmila.

Cattelan (2014) cita a Escola de Vista Alegre e também uma escola do Rio Gamela, onde tinha como professora Laura Rech. Desse período até 1980, muitas escolas foram criadas, mas sem nenhum registro ou aprovação oficial. Os colonos conversavam com as autoridades municipais e solicitavam a criação de uma escola, se comprometiam a ceder o espaço e contribuir com as despesas da escola. $\mathrm{O}$ município contratava uma professora, muitas vezes indicada pelos pais, geralmente uma pessoa da comunidade. Estas escolas somente foram reconhecidas oficialmente a partir de 1980. Até 1964 eram geridas pelo município de Francisco Beltrão, depois por Enéas Marques, contando com a contribuição dos pais com doações de alimentos ou fazendo promoções para arrecadar fundos para a escola.

Cattelan (2014) apresentou um quadro sobre as escolas construídas pela CANGO até 1957. Dentre as escolas que pertenciam ao território de Francisco Beltrão, a autora cita: Escola número "13" - Divisor (Zona Jaracatiá); Escola número “26”-Km 38; Escola número "27”- Nova Esperança (Lontra), escolas que até o ano de 1992 pertenciam ao território de Enéas Marques. A autora destaca dois padrões de escolas construídas em 1954, A e B:

Conforme os Atos Oficiais $\mathrm{n}^{\circ} 1$, de 1954, o município edificou várias escolas, que estabeleceram padrões para a construção adotados desde a instalação da prefeitura: o padrão "A" era construído por uma sala de aula 8x12 metros com tábuas beneficiadas, paredes duplas pintadas 
a óleo e cobertas de telhas francesas (Cattelan, 2014, p. 125).

Conforme a mesma autora, "as casas padrão A eram construídas nos centros residenciais nas Sedes Municipais, encontrando-se concluídas a de Água Branca e estando em construção as de Marmeleiro, Concórdia e Jaracatiá" (Cattelan, 2014, p. 125). Sobre o padrão B, a autora destacou: "as da classe "B" dispõem de residência para o professor, são edificadas nos locais mais distantes, o que facilita a manutenção do mesmo" (Cattelan, 2014, p. 125). Pelos apontamentos de Cattelan podemos identificar uma escola sendo construída no distrito de Jaracatiá em 1954, provavelmente uma das primeiras escolas construídas no município de Enéas Marques.

Quanto ao início de funcionamento das escolas podemos visualizar de forma mais sintetizada no quadro abaixo.

Quadro 2: Início de funcionamento das escolas 1956-1975.

\begin{tabular}{|c|c|c|c|c|c|c|c|c|c|c|c|c|c|c|c|}
\hline Anos & ర్ర & $\begin{array}{l}\overrightarrow{0} \\
\infty\end{array}$ & $\begin{array}{l}\overrightarrow{0} \\
\text { U్ }\end{array}$ & চః & $\vec{\circ}$ & $\begin{array}{l}\overrightarrow{0} \\
\text { న }\end{array}$ & $\begin{array}{l}\vec{\circ} \\
\triangleright\end{array}$ & ๙ั & হু & ఫ̊ㅇ & চे & రి & $\begin{array}{l}\overrightarrow{0} \\
\text { N }\end{array}$ & $\underset{\nabla}{\vec{D}}$ & $\begin{array}{l}\bar{\sigma} \\
\text { u }\end{array}$ \\
\hline Escolas & 4 & 3 & 3 & 7 & 3 & 5 & 3 & 3 & 4 & 1 & 9 & 1 & 1 & 1 & 1 \\
\hline
\end{tabular}

Fonte: Documentos da Secretaria de Educação. Dados organizados pelos autores.

As 49 escolas identificadas estavam localizadas na zona rural, quase todas construídas em madeira, parecidas com uma casa dos colonos, contendo uma sala de aula, varanda e, em algumas delas havia cozinha. A área das escolas não era muito grande, a maioria possuía entre 50 e $80 \mathrm{~m}^{2}$; poucas chegavam a $100 \mathrm{~m}^{2}$ ou mais. A maioria tinha apenas uma sala e algumas duas.

Os professores que atuavam nas escolas eram escolhidos ou indicados pela comunidade, pois poucos possuíam escolaridade superior à $4^{\mathrm{a}}$ série. Estes, geralmente assumiam as escolas nas vilas maiores. Os que haviam concluído o curso primário, até a $4^{\mathrm{a}}$ série, eram considerados como os mais indicados para serem professores nas escolas rurais.

Segundo Fernandes (2016), “a pessoa que soubesse ler e escrever era professor, sabia as quatro operações era professor e tinha muito pouco, mas muito mesmo e eu cheguei aqui e me empurraram para essa função". Também Silva (2015) relata como iniciou suas atividades como professora: "na época eu não tinha nem 15 anos ... As escolas eram longe, os vizinhos decidiram criar uma escolinha na 
comunidade. Como eu já tinha na época a $5^{a}$ série me indicaram para ser professora".

No município de Enéas Marques, encontramos nos documentos da Secretaria Municipal de Educação registro da existência de 53 escolas. Em cada uma delas havia um professor ou mais. No gráfico que segue detalhamos sobre a formação de 48 professores, pois dos demais não encontramos registro de sua formação. No gráfico abaixo detalhamos sobre a formação dos professores do município de Enéas Marques até a década de 1980.

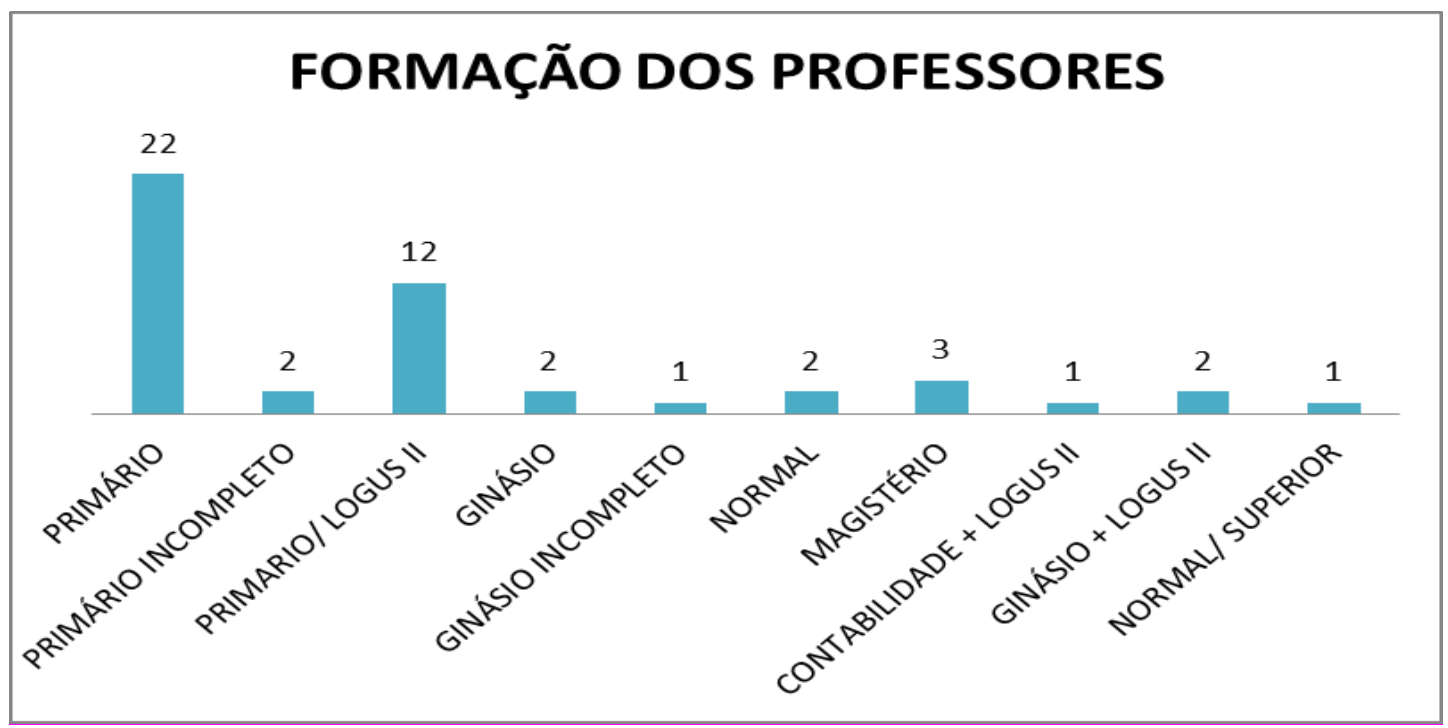

Fonte: Documentos da Secretaria Municipal. Dados organizados pelos autores.

Não foi possível identificar o número exato de professores do município, mas considerando que havia aproximadamente 50 escolas, e que a maioria delas tinha apenas um professor, presumimos que o total de professores era em torno de 60 . Dos 48 professores identificados nos documentos e representados no gráfico, 2 possuíam o curso primário incompleto e 22 o curso completo, 12 possuíam o primário e estavam cursando ou haviam cursado
Logus II, 5 estavam cursando o ginásio ou tinham o ginásio completo mais Logus II, 1 tinha contabilidade mais Logus II e apenas 6 tinha a formação mínima do curso normal/magistério e, destes, apenas um tinha o superior. Os números revelam a precariedade da formação docente no ano de 1980. Metade dos professores que atuavam no município possuía formação no mesmo nível do curso que ministravam, sendo escolhidos para tal função porque 
não havia pessoas mais instruídas, ou seja, eram os que possuíam maior grau de escolaridade. É bom lembrar que na época poucos professores eram concursados.

A partir das normativas da Lei de Diretrizes e Bases da Educação de $1^{\circ}$ e $2^{\circ}$ Graus, Lei $\mathrm{n}^{\mathrm{o}}$ 5.692/1971, implantada gradualmente a partir de 1972, os professores precisaram buscar outros cursos de formação, a saída mais fácil foi a oferta do projeto Logus II no município, para habilitar minimamente os professores. O projeto Logus II era organizado por módulos, tantos módulos para cada disciplina. Os professores vinham para a cidade e levavam alguns módulos para casa para estudar. Um dia por mês havia a aplicação das provas presencias e os professores poderiam fazer várias delas no mesmo dia. Assim, cada professor estabelecia seu tempo de formação. O Logus II foi uma espécie de formação à distância, sem o uso da tecnologia.

Lentamente, alguns professores começaram a se deslocarem para outras cidades, principalmente para Palmas, para fazer a graduação na licenciatura, curta ou plena, em diversas áreas do conhecimento. A partir de 1980 foi organizada no município de Enéas Marques uma equipe pedagógica, para acompanhar a educação, a qual passou a incentivar os professores a continuarem seus estudos, a cursar nível superior, pós-graduação etc., mas até o início da década de 1990, os professores com curso superior ainda eram bem poucos.

\section{Processo de Nuclearização no Município de Enéas Marques}

$\mathrm{O}$ processo de nuclearização das escolas está diretamente relacionado com o processo de industrialização, modernização da agricultura e êxodo rural no Brasil. Segundo Priori et al. "A modernização agrícola no Estado do Paraná foi acompanhada de mudanças que historicamente ocorrem na instalação da base técnica ao campo, como problemas sociais, dentre eles, o êxodo rural, a concentração fundiária ... e o desemprego no campo" (Priori et al. 2012, p. 115). Sobre o processo de modernização da agricultura, Emer afirmou:

Após a modernização da agricultura e expulsão do campo de uma considerável parcela da população, muitas escolas rurais foram desativadas em razão de critérios administrativos, isto é, o reduzido número de crianças em idade escolar não "justificava" a existência da escola. Em diversos municípios a escola rural foi substituída por transporte e constituída uma modalidade de escola denominada nuclearizada, isto é, uma escola centralizada, ampliada e com professores habilitados, para onde converge o transporte de alunos residentes nas linhas e travessões (Emer, 1991, p. 309). 
A década de 1990 foi marcada por algumas mudanças a nível educacional: a principal delas que afetou duramente a educação rural foi $\mathrm{o}$ processo de municipalização do ensino. No Estado do Paraná, a responsabilidade pelas escolas até a $4^{\text {a }}$ série foi repassada para os municípios, o Estado ficou com a responsabilidade com a segunda fase do ensino fundamental de $5^{\mathrm{a}}$ a $8^{\mathrm{a}}$ série. A segunda mudança foi o início do processo de nuclearização das escolas rurais, várias escolas fechadas e os alunos transferidos para escolas núcleos ou para escolas urbanas. As escolas rurais já eram de responsabilidade dos municípios, mas, o processo de municipalização das escolas urbanas acabou estimulando e acelerando a nuclearização das escolas rurais.

A nuclearização ocorreu de forma gradativa, pois foi necessário conscientizar os professores e os pais sobre o fechamento das escolas, o que despertou resistência por parte dos pais, quanto a fechar as escolas e ter que enviar seus filhos para a cidade, ou outra comunidade mais distante precisando percorrer vários quilômetros de ônibus até chegar às escolas. Para concretizar a política de nuclearização, foi necessário investir em transporte escolar e adequar às escolas que receberiam estes alunos. Buscou-se conscientizar os pais sobre a nova organização do ensino que seria por séries e um professor para cada turma.

No decorrer da pesquisa foram encontrados diversos documentos nos arquivos municipais, dentre eles atas de reunião com professores e atas de reuniões com pais de alunos. A partir de algumas atas encontradas nos arquivos da Prefeitura Municipal, podemos compreender como ocorreu o processo de nuclearização das escolas. Inicialmente foram conscientizados os professores sobre as mudanças, depois os pais, o que nem sempre foi tão simples, pois seus filhos eram os mais afetados pelas mudanças que a nuclearização demandava. No ano de 1990 já estavam sendo realizadas reuniões com os pais para falar sobre a nuclearização das escolas, como podemos atestar pela ata da escola XV de Novembro, da comunidade de Bela União: "aos quinze dias (15) do mês de agosto de um mil novecentos e noventa foi realizada na Escola XV de Novembro a reunião com todas as mães da comunidade, a fim dos seguintes assuntos: $1^{\circ}$ conversar com as mães sobre a nuclearização das escolas no nosso município".

Nas reuniões com os pais, nem sempre, o anúncio sobre a nuclearização ou fechamento das escolas era acolhido de forma tranquila, mas permeado de 
insegurança, resistência, exigência de melhores esclarecimentos, bem como insistência para que a escola permanecesse em funcionamento. A ata que segue reflete um pouco essa realidade.

No dia doze de dezembro de um mil novecentos e noventa e dois as nove horas da manhã reuniram-se os pais dos alunos matriculados.... Nesta reunião os pais presentes falaram a respeito da nuclearização dos alunos onde os pais presentes discordaram com a opinião, os pais presentes querem uma reunião com a presença dos prefeitos dos 2 municípios para entrarem num acordo. A pretensão dos pais presentes é que a escola permaneça aqui, construindo o prédio que está em situação precária (E. M, Ata, 1992).

\section{Na Escola São Pedro encontramos os}

pais protestando contra o fechamento da escola.

Aos 3 dias do mês de fevereiro de 1994 reuniu-se os pais dos alunos da escola São Pedro, da Linha Felipe, protestando contra o fechamento da mesma no dia 02 de fevereiro. Nem todos os pais participaram porque já estavam trabalhando, participando quase só as mães pegando-nos de surpresa para assinar um documento que nós não sabemos se foi endereçado pela vossa pessoa. Se for ordem do município, nós queremos veículo disponível para a locomoção das mesmas porque tem crianças pequenas que tem dificuldade em enfrentar escola distante ... Deixando os pais preocupados com a distância em as crianças participar em outra escola, que dá de 3 a $5 \mathrm{~km}$ a mais próxima, "nós pais pretendia que a escola ficasse funcionando no mesmo local. Se assim não for nós estamos dispostos a deixar as crianças sem aula" (E. M, Ata, 1994).

Para os pais as mudanças propostas pela nuclearização geravam insegurança, pois, os filhos frequentavam a escola perto de casa e o professor era uma pessoa conhecida e de confiança. A partir do fechamento da escola na comunidade, os filhos teriam que frequentar outra escola, professores novos e teriam que se deslocar vários quilômetros, precisaria de transporte para levar os alunos.

A Senhora Madalena Nurmberg residente na comunidade de Rio Vitória, tinha uma das filhas estudando numa escola na comunidade e participou das reuniões e conscientização dos pais sobre o fechamento das escolas. Em depoimento oral ela relatou como vivenciaram este momento.

Foi bem difícil porque ali era pertinho para elas ir, o povo dos lugares era tudo conhecido e eles vieram com essa ideia de levar o povo todo para cidade, tinha que ir mais cedo, longe, ir de carro e com as crianças de tudo tipo, de tantos lugares que não era conhecido também. A gente achava quase impossível mais se a ordem era essa, no fim tivemos que concordar e mandar (Nurmberg, M, 2016).

Seu esposo, quando da realização de uma entrevista gravada em 2016, 
descreveu sobre como foi esse período de conscientização dos pais. "Nós num primeiro momento não estávamos de acordo. Disseram que tinha que fazer, pois aqui tinha as salas tudo junto os 4 anos letivos e lá cada aluno teria um professor separado por série". E ainda "devido a distância e locomoção para levar a piazada a gente não estava muito de acordo para mandar os filhos muito longe. Teve um pequeno atrito, mas por fim eles fecharam tudo e nos obrigamos a mandar" (Nurmberg, I, 2016).

No momento de conversa com os pais eram apresentadas algumas justificativas sobre o porquê a nuclearização era importante, para assim ter maior aprovação dos mesmos. $\mathrm{Na}$ ata da Escola São Pedro foram apresentadas algumas prerrogativas sobre o porquê a escola seria fechada e os alunos transferidos para outra escola.

Aos dias 02 do mês de fevereiro reuniu-se os pais e professor da Escola Rural São Pedro para tratar dos seguintes assuntos: Nuclearização, com a transferência dos alunos para a Escola da comunidade do Alto Pinhal. A professora explicou da importância da nuclearização com o novo processo ou método Ciclo Básico que é praticamente impossível adotar o método em uma escola multisseriadas. A professora explicou que também é impossível cumprir o calendário escolar, devido ao trajeto que a professora tem a percorrer até chegar a escola todos os dias, e com as faltas quem iria acabar sendo prejudicada seria as crianças. E explicou as vantagens de frequentar uma escola seriada, com o contraturno para as crianças que não conseguem acompanhar os outros e que a atual escola São Pedro não pode acompanhar o método exigido, daí a necessidade de nuclearizar (E.M, Ata de Reunião, s/ano).

No decorrer da conscientização dos pais sobre as mudanças que viriam, realizavam-se reuniões com os pais, contando com a participação dos professores, Secretária de Educação, vereadores e Prefeito. Em algumas comunidades, além da reunião, eram realizadas visitas às famílias, para conversar e expor mais detalhadamente que mudanças ocorreriam.

Segundo Farias (2013, p. 50), “a Prefeitura define, o Núcleo Regional de Educação encaminha sem questionar, e a Secretaria Estadual de Educação se baseia nos documentos e acaba por sentenciar a cessação da escola". Ou ainda "não havia questionamento sobre o pedido, a não ser onde raras vezes, a comunidade se articulava com forças políticas da região para tentar impedir que a escola tivesse um fim" (Farias, 2013, p. 50). Conforme a mesma autora,

Quando há a proposição de fechamento de uma escola seja por parte do poder público municipal ou 
estadual, segue o protocolo de uma reunião com a comunidade, para explicar os motivos do fechamento da escola. Nos casos em que a comunidade não contesta, em seguida é encaminhado o pedido de cessação para a SEED. Mas, quando há resistência quanto ao fechamento, quando o convencimento não cumpre seu papel, trava-se um jogo de forças, por um lado o poder público querendo cessar, por vários motivos, entre eles justifica o alto custo para a prefeitura manter a escola no campo sendo este superior ao de colocar um ônibus para transportar os estudantes para uma escola, na área urbana. E, do outro lado, a comunidade se organizando para manter a escola no campo, a partir do enfrentamento e resistência. Somente nos casos em que a comunidade se organize e resiste quanto ao fechamento, é que há discussão sobre as particularidades apresentadas pelas famílias que precisam que a escola esteja na comunidade. Isso não acontece, sem embates, disputas e relações de poder (Farias, 2013, p. 50- 51).

\section{A partir de Farias}

identificamos duas realidades relacionadas ao processo de fechamento das escolas: o primeiro foi/é o aviso de fechamento de uma escola que foi/é aceito pelos pais. O segundo foi/é o aviso de fechamento e a comunidade resistiu/resiste, discordou/discorda dessa medida e buscou/busca de várias formas para que a escola permanecesse/permaneça na comunidade. No segundo caso, obrigou/obriga o poder público apresentar os motivos para fechar, procurando convencer a comunidade. Essa situação exigiu/exige maior discussão, reuniões para que o convencimento fosse/seja a última palavra.

Bonetti, ex-prefeito do município entre 1982-1988 e 1993-1996, entrevistado em 2016, detalhou como ele viu o processo de nuclearização:

Foi uma normativa, foi uma política nova ... A questão de otimizar recurso público foi também um argumento. Eu lembro que era uma política onde se pretendia dar ao aluno, professores e servidores uma melhor estrutura na escola. Uma escolinha pequena seria difícil fazer aquilo que foi possível fazer num núcleo. É claro que o deslocamento do aluno era uma preocupação, a questão de sair de casa mais cedo, a questão de segurança, as condições das estradas, a própria condução dos ônibus na época, mas se fazia com muita dedicação, se fazia com muita cautela, muito respeito, havia muito diálogo e o resultado na minha opinião foi positivo, mas eu diria que o principal fator, na época, não foi esta questão de otimizar recurso público, foi também, mas o principal foi dar uma melhor condição aos alunos, numa escola mais bem estruturada (Bonetti, 2016).

Bonetti foi prefeito no município de Enéas Marques por duas gestões, na primeira participou do processo de reforma das escolas e ampliação do espaço escolar. $\mathrm{Na}$ segunda, participou do movimento de reorganização das escolas que se tornaram escolas núcleos e, segundo ele acompanhou diretamente, somente o 
fechamento da Escola de Bela União. Bonetti (2016) expressou como foi esse processo: "eu lembro que foi necessário muitos dias de conversa, diálogo com os pais". Detalhou também como foi a organização do transporte escolar para que os alunos pudessem frequentar outras escolas.

$\mathrm{Eu}$ participei pessoalmente do processo de elaboração de editais e coordenar esse processo de licitação para escolher os transportadores através do que a lei determinava na época que era através da concorrência pública, a definição de linhas e inclusive do convencimento dos pais que alguns tinham resistência que o filho tinha que andar 500 metros. Algum sacrifício teria que ser feito, sair de casa um pouco mais cedo, o ônibus não pode entrar em todas as propriedades, vai ter uma linha principal e cabe aos pais então conduzir o seu filho na melhor segurança possível até $o$ ponto de parada dos ônibus. Tudo era estudado para diminuir riscos e levar os alunos mais próximo da residência, desde que isso não implicasse no trajeto em relação ao horário de chegada da escola (Bonetti, 2016).

Nas escolas rurais, o professor realizava todas as atividades sozinho. Com a nuclearização e a concentração dos alunos nas escolas que foram escolhidas para serem núcleos, houve necessidade de nova organização, mais pessoas envolvidas, diversos professores, merendeira, zeladora, diretora, secretária, pedagoga etc. Os professores que atuavam nas escolas onde as atividades cessaram foram remanejados para as outras escolas juntamente com os alunos e puderam continuar seu trabalho.

Hoffelder (2016) foi diretora na Escola Municipal Criança Feliz, localizada na zona urbana, a qual recebeu um número expressivo de alunos das escolas fechadas, justamente nesse período de transição que foi a nuclearização das escolas. Em depoimento oral gravado em 2016, ela afirmou: "Foi um momento muito difícil, complicado porque como a gente tem o filho da gente, no interior eles são acostumados com a família naquele ambiente e tirar eles foi a mesma coisa que tirar o filho do seio materno". Segundo ela,

Eles vieram para um lugar que era totalmente diferente, depois eles foram gratificados porque aqui eles tiveram turmas por série não mais escolas multisseriada. Quando a gente começou o trabalho era multisseriado tinha de $1^{\text {a }}$ a $4^{\text {a }}$ série junto, então trabalhava com uma série, deixava essa trabalhava com a outra, as 4 séries junto e foi pensando nisso que houve a nuclearização para facilitar mais o trabalho e fazer com que os alunos também conseguissem um aprendizado melhor (Hoffelder, 2016).

Hoffelder (2016) destacou como os pais acataram a mudança de escola pelos filhos: "teve muita reserva dos pais, não queriam que fechasse as escolinhas do 
interior, mas hoje eu acho que eles acabaram aceitando com o tempo e viram que você estava ali para ajudar, para contribuir com eles". Marques (2016) foi professora nas escolas multisseriadas e atuou também nos diversos níveis de ensino. Também trabalhou como diretora de escolas e na Inspetoria de Ensino. Segundo ela, a nuclearização favoreceu aos professores na busca por maior formação. "Eles tiveram uma chance de ter uma formação melhor e vieram todos aqui para cidade, trouxeram as escolas com professores e passou a ser seriadas".

Abreu (2016) foi professor no município de Enéas Marques e atualmente (2017) trabalha como Secretário de Educação no município de Nova Esperança do Sudoeste. Ele delineou o que provavelmente motivou a nuclearização das escolas: "acredito que a intenção era fechar as escolas, reunir as escolas porque elas estavam ficando com poucos alunos exatamente para ser melhor administradas e geradas menos despesas". $\mathrm{Na}$ sua compreensão, "a necessidade de nuclearizar não foi tanto por modernismo nem por ter uma melhor educação, um melhor trabalho, mas por exigência de controlar os gastos públicos".

Campos (2015), professora da rede municipal, também atuou na Secretaria de Educação por mais de 20 anos, coordenando a organização das escolas e sendo responsável pelo acompanhamento dos professores e alunos. Ela relatou como foi vivenciada a nuclearização das escolas.

Foi um processo bem complicado. Começou a nuclearização das escolas quando houve a municipalização do ensino, o estado repassou as escolas estaduais para o município que ficaria responsável pelas escolas de Pré, de educação infantil e o ensino fundamental de primeiros anos; o estado ficaria com a segunda fase do ensino fundamental que antes era de $5^{\mathrm{a}}$ serie até $8^{\mathrm{a}}$ serie e segundo grau e a União ficaria com o terceiro grau. Então houve uma sobrecarga para os municípios quando houve a municipalização da educação. Aqui nos tínhamos escolas que funcionava no mesmo prédio que depois foi separado, a Escola Arnaldo Busato atendia, de Pré até o segundo grau e foi separado (Campos, 2015).

Pelo depoimento de Campos percebemos que o município não estava preparado para esta mudança, mas a situação exigia nova organização e os encaminhamentos foram sendo realizados. A Escola Arnaldo Busato funcionava no mesmo prédio da Escola Municipal Criança Feliz e precisou ser separada, pois, a escola receberia uma demanda grande de alunos de $1^{\mathrm{a}}$ a $4^{\mathrm{a}}$ série.

Todos os municípios do Paraná começaram a nuclearização das escolas. Foi bem traumático no começo. Os pais eram muito resistentes de tirar a escola porque era um ambiente cultural deles. 
Nessa época houve mais transporte escolar. As mães tinham muito medo que os alunos iam se perder e mesmo que a cidade era pequena, que eles estavam correndo riscos maior vindo para a cidade. A gente sempre tentou explicar para eles a diferença de uma escola aonde cada professor ia atender a uma série separada de que um professor com todas as series ... De uns tempos pra cá a população só reduziu no município, por exemplo tem comunidades que a escola fechou com 8 alunos, outras com 10 com 4 série, enquanto outras escolas com 40 alunos e a escola também foi nuclearizada. Foi bem difícil para administração porque de repente tu se viu com uma proposta dessas e teve que organizar o seu sistema totalmente diferente. $\mathrm{Na}$ parte documental teve a cessação de funcionamento das escolas que é uma burocracia. A nuclearização foi gradativa (Campos, 2015).

Pelo depoimento de Campos (2015) identificamos alguns desafios que já foram citados anteriormente, como a resistência dos pais ao fechamento das escolas, insegurança pelos filhos frequentarem as escolas na cidade, realidade nova, professores novos e desconhecidos. Percebemos a mudança do ensino multisseriado para seriado, a disponibilização de transporte escolar para levar os alunos à nova escola e como o processo de nuclearização gerou uma grande papelada a ser preenchida pelos responsáveis pela educação.

Hoje me pergunto até que ponto isso é certo, é correto? Na parte funcional, administrativa e econômica teve ganhos, mas culturalmente eu me pergunto hoje se isso contribuiu ou não? Tem vários pensadores que dizem que não se deve fazer a nuclearização, mas como manter essas escolas com 10 ou 30 alunos? $\mathrm{Tu}$ imagina turmas de 10 ou menos onde hoje o recurso para a educação é tudo voltado para o número de alunos e número de professores. Para ter qualidade você tem que se sujeitar aos entraves de mandar o teu filho pequeninho de 6 anos fazer $20 \mathrm{~km}$ dentro de um ônibus enquanto ele podia com 10 minutos de caminhada chegar a escola. Mas eu como professora ainda acredito que foi melhor, do que você ficar batendo em cima de uma coisa que não tem concerto. As escolas muito pertinho uma tirava aluno da outra e para o município fazer vários núcleos num município pequeno como é o nosso não era viável (Campos, 2015).

Na citação anterior observamos dois lados da nuclearização: o das mudanças ocorridas na parte funcional, administrativa e econômica; e o da retirada da escola da comunidade, que era considerada um espaço de construção de conhecimento e cultura. Ambiguidades que permanecem na história e que apresenta defensores para ambos os aspectos.

$$
\text { Segundo Bonetti (2016) “a }
$$
diminuição de alunos por escola era uma realidade, havia na época uma saída um tanto expressiva de agricultores que estavam indo para centros urbanos para buscar renda como Joinville e outras cidades do Brasil”. 
No ano de 1992 ocorreu a separação dos territórios de Enéas Marques e Nova Esperança do Sudoeste. As escolas que pertenciam ao território de Enéas Marques, mas que ficavam na região onde se estabeleceu o novo município, passaram a ser de responsabilidade de Nova Esperança, restando no território de Enéas Marques em torno de 30 escolas. A partir de 1991 as escolas rurais foram sendo fechadas e os alunos encaminhados para outras escolas, ou escolas-núcleo. Os alunos, inicialmente, foram transferidos para as escolas municipais de: Vista Alegre, Criança Feliz (urbana), Cristo Rei, Rio Bocó, Pinhalzinho, e Alto Pinhal, e posteriormente restaram duas escolas: Pinhalzinho e a urbana. Segundo Farias (2013, p. 56), nas décadas de 1980, 1990 e 2000 foram cessadas 31 escolas no município de Enéas Marques e 18 em Nova Esperança. Nossa pesquisa revelou que foram 36 as escolas fechadas entre 1987 e 2001. Em 1987 uma escola fechada, de 1991 a 1994 foram cessadas 19 escolas, de 1996 a 2001 mais 16 escolas, totalizando 36 cessações.

No município de Enéas Marques foram encontrados registros de 53 escolas que a partir da década de 1990 começaram a ser cessadas. Hoje, há em funcionamento na rede municipal de Ensino, situadas na Zona urbana: Centro Municipal de
Educação Infantil Anjo da Guarda e Escola Municipal Criança Feliz - Educação Infantil e Ensino Fundamental e uma na Zona Rural na comunidade de Pinhalzinho: Escola Municipal do Campo Treze de Maio - Educação Infantil e Ensino Fundamental. $\mathrm{Na}$ rede estadual permanecem duas situadas na zona rural: Escola Estadual do Campo Pinhalzinho Ensino Fundamental e Escola Estadual do Campo Vista Alegre - Ensino Fundamental e uma na zona urbana: Colégio Estadual Castro Alves - Ensino Fundamental e Médio.

No município de Nova Esperança do Sudoeste estão em funcionamento na zona urbana uma Escola Municipal Visconde de Mauá - Educação Infantil e Ensino Fundamental e o Colégio Estadual Nova Esperança e na zona rural Escola Rural Municipal Angastão Cruz - Ensino Fundamental na comunidade do Rio Gavião e a Escola Rural Municipal Santo Antonio - Ensino Fundamental, localizada em Barra Bonita.

Aproximadamente 50 escolas foram fechadas entre a década de 1980, 1990, 2000 e 2010 do município de Enéas Marques e Nova Esperança do Sudoeste. Os alunos foram remanejados para as escolas que estão em funcionamento, mas, a maioria passou a frequentar as escolas 
localizadas na zona urbana, necessitando do uso de transporte escolar.

\section{Considerações Finais}

A partir das leituras sobre o processo de nuclearização e contato com a realidade de Enéas Marques foi possível perceber que essa mudança foi consequência de um período histórico, político e econômico, mas, principalmente de uma política governamental, visando reduzir os gastos com a educação. Uma medida imposta de cima para baixo. Os envolvidos nesse processo, os professores e alunos não foram consultados sobre isso, apenas sofreram as consequências dessa prerrogativa.

No município de Enéas Marque e Nova Esperança do Sudoeste (que até 1992 faziam parte do mesmo território), foram cessadas aproximadamente 50 escolas, e os alunos remanejados para outras escolas.

Embora o discurso utilizado no período de fechamento das escolas rurais foi a nuclearização, como garantia da melhoria da qualidade da educação e economia de gastos, o que ocorreu de fato foi a urbanização das escolas, mediante a oferta de transporte escolar. No município de Enéas Marques, atualmente existe apenas uma escola na zona rural, que atende as crianças até o $5^{\circ}$ ano. Esse fato é lamentável, pois, a população rural do município ainda é superior a $60 \%$.

O município de Enéas Marques é essencialmente agrícola, a população permanece em sua maioria no campo e o fechamento de tantas escolas não pode passar despercebido, mas deve levar a reflexão e análise dos fatores e justificativas apresentadas para motivar tal procedimento. Por ser uma região, essencialmente agrícola, tal característica precisa ser valorizada. A política mais correta seria manter as escolas na zona rural, valorizando e incentivando os alunos a permanecerem no campo, com possibilidades de estudar, sem necessitarem se deslocar para a zona urbana.

O fechamento das escolas rurais/do campo via o processo de nuclearização ou urbanização foi justificado pela diminuição das pessoas no campo, isso é fato. Todavia, a política de nuclearização acabou estimulando as famílias a abandonarem o campo, pois, muitos pais não aguentaram ver seus filhos submetidos, diariamente, às condições degradantes do transporte escolar. A nuclearização foi um modismo que acabou convencendo vários prefeitos a fechar escolas, mesmo em município que tinham dois terços da população na zona rural. A nuclearização produziu impactos diretamente na vida dos agricultores, que, 
rapidamente perderam a identidade de comunidade, acarretando no abandono acelerado da vida no campo.

\section{Referências}

Brasil. Lei $\mathrm{n}^{\mathrm{o}} 5.692$ de 11 de agosto de 1971. Fixa as Diretrizes e Bases para o Ensino de $1^{o}$ e $2^{o}$ graus, e dá outras providências. Recuperado de: http://www.planalto.gov.br/ccivil_03/leis/L 5692.htm.

Cattelan, C. (2014). Educação Rural no município de Francisco Beltrão entre 1948 a 1981: A Escola Multisseriada. Francisco Beltrão. (Dissertação de Mestrado) Universidade Estadual do Oeste do Paraná, Paraná.

Damasceno, M. N, \& Beserra B. (2004). Estudos sobre educação rural no Brasil: estado da arte e perspectivas. Educação $e$ Pesquisa, 30(1), 73-89. DOI: http://dx.doi.org/10.1590/S1517$\underline{97022004000100005}$

Emer, I. O. (1991). Desenvolvimento Histórico do Oeste do Paraná e a Construção da Escola. (Dissertação de Mestrado) Fundação Getúlio Vargas, Rio de Janeiro.

Farias, M. I. (2013). Os processos de Territorialização e Desterritorialização da Educação do campo no Sudoeste do Paraná. (Dissertação de Mestrado) Universidade Estadual Paulista, Presidente Prudente.

Laste, D. D. (2000). Histórico da Emancipação Política de Enéas Marques $P R$. (Trabalho de Conclusão de Curso). Faculdades de Palmas, Palmas.
Lazier, H. (1997). Análise Histórica da Posse de Terra no Sudoeste Paranaense. Francisco Beltrão, PR: Grafit.

Le Goff, J. (1994). História e Memória. Campinas, SP: Editora da UNICAMP.

Martins, R. S. (1986). Entre Jagunços e Posseiros. Curitiba, PR: S/I

Netto, J. P. (2011). Introdução ao Estudo do Método de Marx. São Paulo, SP: Expressão Popular.

Niederheitmann, L. C. (1986). Das matas primitivas a Polo de uma RegiãoAbordagem Histórica de Francisco Beltrão. (Trabalho de Curso de Especialização). Faculdade Estadual de Filosofia, Ciências e Letras de Guarapuava, Guarapuava.

Nosella, P., \& Buffa, E. (2006). As pesquisas sobre instituições escolares: balanço crítico. In Anais Colóquio sobre Pesquisa de Instituições Escolares. Campinas, SP: UNICAMP/São Paulo, SP: UNINOVE.

Padis, P. C. (1981). A Região Sudoeste: o que é e como foi ocupada. In Formação de uma economia Periférica: o caso do Paraná. São Paulo, SP: HUCITEC/Curitiba, PR: Secretaria da Cultura e do Esporte do Governo do Estado do Paraná.

Priori A. Possamai. L. R. ... et al... (2012). A modernização do campo e o êxodo rural. In Priori A., Possamai. L. R. ... et.al... História do Paraná: séculos XIX e XX (pp. 115-127). Maringá, PR: Eduem. DOI: http://dx.doi.org/10.7476/9788576285878

\section{Revistas ou Documentos}

Enéas Marques. (1988). Enéas Marques em Revista. Enéas Marques: nossa História, 
nossa Gente. Departamento de Educação e Cultural de Enéas Marques. Pato BrancoPR: Gráfica KAMARO.

Enéas Marques. Ata de 15 de agosto de 1990. Escola XV de Novembro. Arquivo da Secretaria Municipal de Educação.

Enéas Marques. Ata de 12 de novembro de 1992. Ata de reunião com pais. Arquivo da Secretaria Municipal de Educação.

Enéas Marques. Ata de 3 de fevereiro de 1994. Escola São Pedro. Arquivo da Secretaria Municipal de Educação.

Enéas Marques. Ata de 2 de fevereiro s/ano. Escola São Pedro. Arquivo da Secretaria Municipal de Educação, s/ano.

Paraná. Lei no 92 de 25 de agosto de 1961: A Vila Jaracatiá foi elevada à categoria de Distrito administrativo. Recuperado de: http://www.legislacao.pr.gov.br.

Paraná. Lei $\mathrm{n}^{\circ} 4.823$ de 18 de fevereiro de 1964: criado o município de Enéas Marques, Pinhão e Salto do Lontra. Recuperado de: http://www.legislacao.pr.gov.br.

\section{Relatos Orais}

Abreu, A. I. N. (2016). Depoimento oral em 06 de junho de 2016. Informações complementares: casado, instrução: ensino superior: Gestão de Empresa e Gestão Pública Profissão: Servidor Público, professor, Secretário de Educação no município de Nova Esperança do Sudoeste.

Baio, B. W. (2016). Depoimento oral em 26 de novembro de 2016. Informações complementares: viúva, instrução: de $1^{\mathrm{a}}$ a $4^{\mathrm{a}}$ série. Profissão: costureira.

Bonetti, A. C. (2016) Depoimento oral em 26 de novembro de 2015. Informações complementares: casado, Instrução: Profissão: técnico em Agropecuária, prefeito no município de Enéas Marques 1983-1988 e 1993-1996.

Campos, C. M. D. (2015). Depoimento oral em 07 de julho de 2015. Informações complementares: casada, instrução: nível superior, profissão: professora, católica.

Fernandes, J. A. (2016). Depoimento oral em 02 de fevereiro de 2016. Informações Complementares: viúva, instrução: $2^{\circ}$ grau, profissão: professora, católica.

Hoffelder, M. do C. V. (2016). Depoimento oral em 21 de janeiro de 2016. Informações complementares: casada, Instrução: nível superior. Profissão: professora e diretora. Atualmente está aposentada.

Marques, R. P. (2016). Depoimento oral em 21 de janeiro de 2016. Informações complementares: viúva, Instrução: Pedagogia e Especialização em Administração Escolar. Profissão: professora: 32 anos, diretora 9 anos e 3 anos como Inspetora Escolar. Aposentada a 20 anos.

Mendes, J. D. (2016). Depoimento oral em 12 de fevereiro de 2016. Informações complementares: Casado. Instrução: $2^{\circ}$ grau. Profissão: agricultor, pedreiro, gerente de produção.

Nurmberg, I. (2016). Depoimento oral em 2 de fevereiro de 2016. Informações complementares: casado, instrução: $1^{\mathrm{a}}$ série do $2^{\circ}$ grau. Profissão: agricultor.

Nurmberg, M. (2016). Depoimento oral em 2 de fevereiro de 2016. Informações complementares: casada, instrução: primário. Profissão: agricultora.

Silva, A. M. B. (2015). Depoimento oral em 27 de junho de 2015. Informações 
complementares: casada, instrução: magistério, profissão: professora, católica. Casada com o cartorário João Ramilio da Silva.

Wessling, J. (2016). Depoimento oral em 26 de novembro de 2016. Informações complementares: solteiro, instrução: $2^{\circ}$ ano primário. Profissão: agricultor.

\footnotetext{
${ }^{\mathrm{i}}$ A pesquisa intitulou-se: História da Educação do Município de Enéas Marques - 1960 a 1992 e foi desenvolvida junto ao Programa de Pós-Graduação em Educação, nível de mestrado, da Universidade Estadual do Oeste do Paraná - UNIOESTE campus de Francisco Beltrão, entre 2015 e 2017, sob a orientação do professor André Paulo Castanha.

ii Jaracatiá: nome dado ao distrito devido a grande quantidade desta árvore nativa da região. O Jaracatiazeiro produz uma fruta semelhante ao mamão, é uma espécie de mamoeiro do mato, embora menor. Era muito utilizado na fabricação de doces caseiros.

iii $\mathrm{O}$ nome foi sugerido pelo Deputado Arnaldo Busato, em homenagem a Enéas Marques dos Santos, cidadão curitibano, professor na Universidade do Paraná, Escritor, Promotor Público e um dos fundadores da Academia Paranaense de Letras.

iv $\mathrm{O}$ depoimento de Wessling foi mantido a grafia utilizada por Laste (2000, p. 102-103).

${ }^{\mathrm{v}}$ Educandário São José foi um colégio coordenado pelas Irmãs Escolares de Nossa Senhora e atendia a alunos de $1^{\mathrm{a}}$ a $4^{\mathrm{a}}$ série. Iniciou suas atividades em 1962 e permaneceu até 1968/1969.
}

Recebido em: 23/08/2017 Aprovado em: 12/09/2017 Publicado em: 15/12/2017

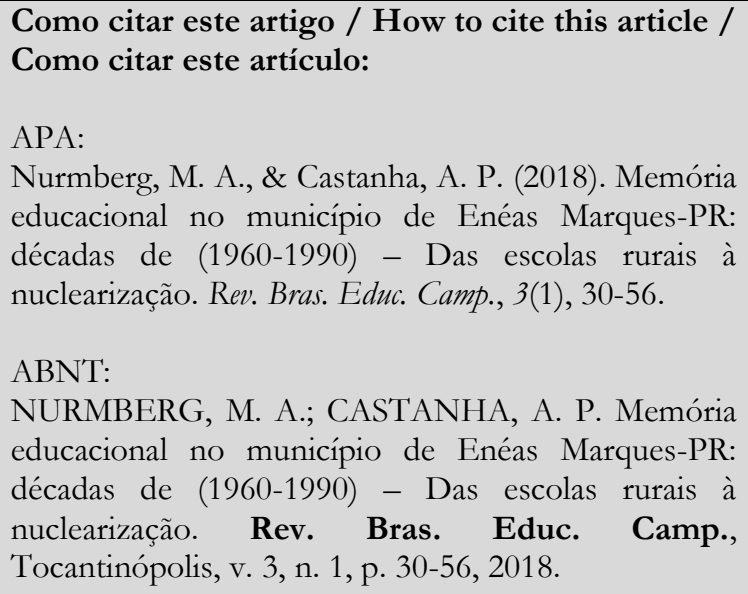
educacional no município de Enéas Marques-PR: décadas de (1960-1990) - Das escolas rurais à nuclearização. Rev. Bras. Educ. Camp., 3(1), 30-56.

ABNT:

NURMBERG, M. A.; CASTANHA, A. P. Memória educacional no município de Enéas Marques-PR: décadas de (1960-1990) - Das escolas rurais à nuclearização. Rev. Bras. Educ. Camp., Tocantinópolis, v. 3, n. 1, p. 30-56, 2018.

\section{ORCID}

Maricélia Aparecida Nurmberg

(iD) http://orcid.org/0000-0003-2549-6869

André Paulo Castanha

iD http://orcid.org/0000-0003-0571-0960 